\title{
INTEGRATED LEARNING DESIGN OF AN ENGINEERING TECHNOLOGY SUSTAINABILITY AND ETHICS COURSE
}

\author{
Greg Zilberbrant \\ Adjunct Lecturer, Sustainability \& Ethics \\ McMaster University, School of Engineering Technology \\ Hamilton, Ontario, Canada \\ zilberg@mcmaster.ca
}

\begin{abstract}
McMaster University's School of Engineering Technology (SET) offered a unique course structure to students in their final undergraduate term in the 2015-2016 academic year. The intention of the program chair and instructor was to deliver a course that taught sustainability and ethics in a context that would be applicable to 105 Bachelor of Technology (B.Tech.) engineering technology students preparing to commence their careers at the end of the term. The course focused on the delivery of a final project of the students' choosing that connected to a real-world sustainability issue supported by weekly lectures and testing. The unique delivery style was an experiential learning approach mimicking the dynamics of a real-world project involving client and stakeholder management - concepts that the students were introduced to in prerequisite courses. The project criteria stipulated a "new-worthy" topic which forced the students to be up-to-date and adjust their project work throughout the term based on changes in the media interest, public opinion, or political involvement. Students were challenged to not only look at the problem and address the applicable environmental, social, and economic aspects but to further develop communication strategies within the political context and societal acceptance/understanding of the issue. The evaluation of the course success is reviewed based on student feedback and a formal focus-group session conducted by McMaster Institute for Innovation \& Excellence in Teaching \& Learning (MIIETL) which highlighted students "felt engaged with the material and described the project as their 'greatest intellectual challenge' of the B.Tech. program." For the purpose of knowledge sharing, this paper will discuss the course design, innovative instructional approach, group project attributes and outcomes from a student the focus-group.
\end{abstract}

Keywords: Sustainability education; course design; innovative course delivery; experiential learning; engineering technology program; professional skills; project management; stakeholder analysis

\author{
Allan MacKenzie \\ Program Chair, Management \\ McMaster University, School of Engineering Technology \\ Hamilton, Ontario, Canada \\ mackenza@mcmaster.ca
}

\section{INTRODUCTION}

This paper will discuss a final term Sustainability and Ethics course that was introduced in the Bachelor of Technology (B.Tech.) program at the McMaster School of Engineering Technology (SET) in the fall of 2015. The intention was to develop an experiential learning approach which integrated and mirrored the dynamics of a real-world project involving client and stakeholder management into the context of the course to further prepare students commencing their professional careers at the end of the term. For the purpose of knowledge sharing, this paper will discuss course design, the innovative instructional approach, project attributes, and outcomes from the end of term student focus group.

B.Tech. is a skills-based engineering technology and management program at the university level. The program is a partnership between McMaster University Faculty of Engineering and Mohawk College's School of Engineering Technology. The program combines traditional lectures with hands-on experience in high-tech modern labs, as well as real-life industry experience (a 12-month workplace co-op is mandatory for students to graduate) in three areas of specialization: Automotive and Vehicle Technology, Biotechnology, and Process Automation Technology. The B.Tech. program also uniquely blends engineering technology with management and societal courses to explore the human side of engineering. The aim is to produce graduates equally savvy in technical as well as management skills, and who have breadth of perspective to tackle broadbased engineering issues in creative and practical ways.

It is well understood, and has been extensively highlighted in the literature that "the goal of engineering is not just delivering the best technical solution, but delivering a solution that is best for all, humans and nature included" [1]. In the Roadmap to the Future of Engineering Practice Research and Education, Duderstadt [2] explains, "the changing workforce and technology needs of a global knowledge economy are dramatically changing the nature of engineering practice, demanding far broader skills than simple the mastery of scientific 
technological disciplines.” Engineers and engineering education is essential for bringing about sustainability, including the development and implementation of sustainable technologies and sustainable system innovations [3].

The instructional methods and curriculum design required for creating a bridge between sustainability education and professional engineering practice can be difficult to realise in a traditional engineering instructional approach. Sustainable design and development is surrounded by uncertainty and ambiguity. The modern engineer needs to be equipped with the knowledge and skills to manage this uncertainty and make judgments about the best course of action based on the available evidence [4]. This requires engineers of the 21st century to have creative problem-solving skills and to "evaluate the implications of their solutions beyond their immediate technical context" [5]. Wise et al. [6] conducted a four-year longitudinal study of intellectual development in engineering undergraduates. Their results indicate that without active learning and team-based projects, students fail to progress adequately in terms of intellectual growth. In turn, they often lack the critical thinking skills, confidence, and creativity needed to successfully evaluate the impact of corporate decisions on the environment and society. Queis [7] suggests sustainable development demands a new pattern of teaching and a particular kind of educational practice. The teacher is a learning enabler, rather than a knowledge giver and educators act as role-models and learners. Learning takes place in relation to real-life situations and there is a focus on practical and real-life experiences.

The intention of the B.Tech. Sustainability and Ethics course was to begin to develop these skills and this understanding of sustainability in students, and to do so in a way that enables graduates to apply these principles and skills in their future professional activities. To grow graduates who do not think of global sustainability issues as 'somebody else's problem', or possibly even 'a marketing device to attract green-consumers', but are able to integrate the objectives of (i) increasing real long-term social, economic and environmental benefits, and (ii) work collaboratively to achieve this goal, while (iii) acting on evidence rather than assumptions or ideology, embedding good practice into their professional thinking [8].

\section{COURSE STRUCTURE}

McMaster University engineering department offers a number of courses in sustainability and ethics, including final year courses focused on the application of sustainability principles. This is not dissimilar to other universities which may offer elective or core courses focused on sustainability and ethics. The B.Tech. final term Sustainability and Ethics course was unique in approach, mimicking the dynamics of a real-world project involving client and stakeholder management.

\subsection{Course Overview}

The course was divided into two distinct components. The first component included the lectures supplemented with readings and digital material that was reinforced with individual weekly online quizzes for one hour per week. The general themes covered throughout the term were focused on providing a knowledge platform for students to understand the inextricably linked dimensions of sustainability. The topics covered tied into the second component of the course which consisted of a progressive group project. The general themes included:

- The history of sustainable design and its relevance for today's engineering technology professional

- The role of corporate and industry-wide policy in the sustainability movement

- The environmental and economic approach, tools and policy instruments of sustainable design

- A review of available information, tools, and methodologies of information gathering through a sustainability context

- An overview of the impact of public and media opinion within the sustainability arena

- The challenges of measuring sustainability and how to balance the environmental, social, and economic needs in valuation

- The tools and application of measured sustainability

- Social impact as a measure of environmental and economic sustainability

It is importance to note that although sustainability concepts are presented throughout the Bachelor of Technology program there is no formal curriculum framework that scaffolds sustainability material outside of this course at the time that it was taught. In the future our scaffolding approach would involve dividing topics into smaller pieces, which are delivered to students continuously throughout their B.Tech. degree. These pieces are integrated into required courses, so students learn to consider sustainability in all their decisions. Each piece of curricula seeks to build on, and reinforce, the last [9]. As such, the merits of this course can be evaluated individually and could, arguable, be transferrable with the appropriate instructional staff support and subject matter knowledge.

\subsection{Progressive Group Project}

The progressive group project was structured within the context of a public policy application. This was chosen as a starting point but students were not restricted to only those topics with a public sector application - 
they did, however, need to consider the sustainability relevance of the challenge or problem that was being addressed in which their proposed recommendations could have considered a solution that required action in all sectors.

Each group was asked to consider themselves as a specialized consulting firm evaluating the environmental, social, and economic impact of changes to technology, public policy, and business practices. Groups were to conduct an investigation of any emerging high-profile issue of concern at the municipal, provincial, or federal government level with the teaching assistant and instructor acting as the client's representative (lower rank employee) and the client (management/executive level employee), respectively. Each student group selected a topic of their choosing that was a persuasive issue for the client due to pressures from citizens, NGOs, and the business community and to take a stance on that specific issue.

Throughout the term, students met with the teaching assistant and instructor based on the three-week rotating schedule as shown in Fig.1. Each meeting was for 30-40 minutes with the exception of the final presentation, for which 60 minutes was allocated.

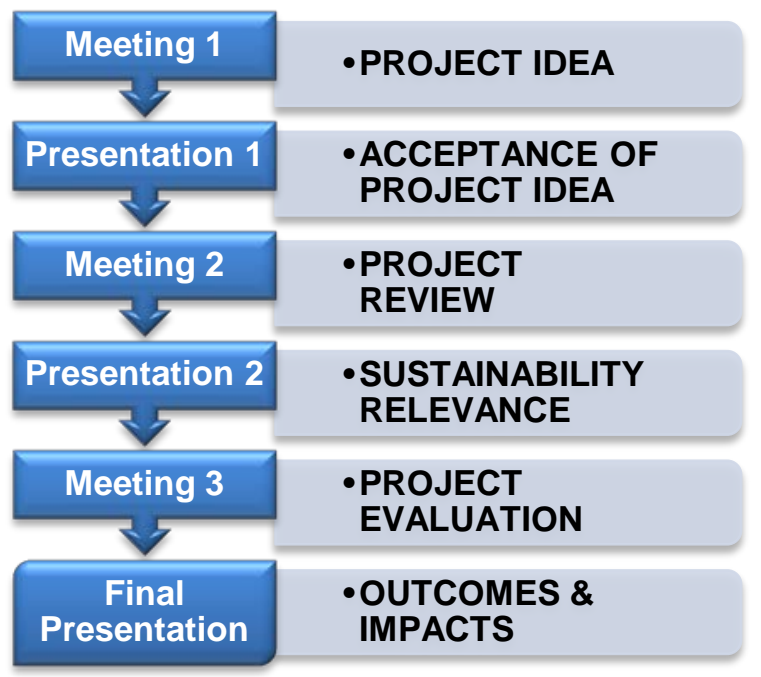

Fig.1. Meeting rotation

Students were expected to present information relative to each meeting topic. Student groups had to provide an agenda in advance of the meeting and produced meeting minutes post-meeting. The impetus was on the students to structure the agenda and run the meeting with guidance provided on the general expectations for each meeting or presentation. The nomenclature of 'meeting' and 'presentation' were for the benefit of the students to differentiate facetime between the teaching assistant and the instructor. Students were encouraged to have a structured discussion for each engagement whether via a PowerPoint presentation, physical documentation, or verbal delivery for the meeting with the teaching assistant. All engagements with the instructor students were expected to have a visual (PowerPoint, Prezi, etc.,) presentation.

The meetings and presentations were outlined as follows including the theme and expectations. However, as previously highlighted, students had the freedom to propose the agenda as they saw fit based on their progress.

- $\quad$ Meeting 1 (with TA): Project Idea

Expectation: Leave with a chosen project topic based on an engaged discussion and justification of the ideas presented. Alternatively, the group will leave with a list of actions/research that needs to be completed before Presentation 1 with the instructor.

- Presentation 1 (with Instructor): Acceptance of Project Idea

Expectation: Present the background research, the relevance of the project within a sustainability framework, and why the evaluation of the project will have meaningful outcomes. Instructor agrees to the topic - outright or with modification.

- $\quad$ Meeting 2 (with TA): Project Review Expectation: Provided a summary of positions of existing NGOs/academia, current practices of the business community in the field, actions and/or positions of other jurisdictions, existing knowledge on the technology and/or practice, the relevant media coverage and public opinion.

- Presentation 2 (with Instructor): Sustainability Relevance

Expectation: Present the policy implications and/or drivers that are relevant to the project, the sustainability design or sustainability challenges the project is addressing, and the metrics that are being used to evaluate the success of the project inclusive of research presented in Meeting 2. Instructor agrees on the review focus/metrics and provided additional direction as needed.

- $\quad$ Meeting 3 (with TA): Project Evaluation

Expectation: Evaluate the government's options on action (if any) as it related to public policy; evaluate the metrics that are relevant and those that would be expected by stakeholders (if different); evaluate and quantify the environmental, social, and economic impact of the processes change(s) or the impact of the "do nothing approach"; evaluate the potential responses from stakeholders and potential media reaction. 
- Final Presentation (with Instructor and guests): Outcomes/Impacts Expectation: All information presented in Meeting 3 as well as recommendations on next steps including (but not limited too) a policy roll-out strategy and communication strategy.

\subsection{Progressive Group Project Unique Elements}

2.3.1 Three-Week Rotation of Learning. A three-week rotation schedule was used for the project meetings to allow students sufficient facetime with both the teaching assistant and the instructor while maintaining a reasonable class size (40-60 students), and allowing for a standard instructional schedule of three hours of class time per week.

In their groups, students would meet with teaching assistant in week one; followed by a meeting with the instructor in week two; then a working week during week three. The cycle would repeat three times for each group during the term. The schedule was staggered to allow up to nine groups (three groups per rotation) per course section. The three-week rotation schedule also allowed the student to complete work leading up to the next series of meetings.

2.3.2 Dynamic Nature. The dynamic nature of the group project was a unique component of the course. The project groups did not go as far as interacting with realworld clients but the project themes were also not predetermined. Groups had to pick topics that were, at the time of course, evidently part of the public discourse and newsworthy. Example of some topics chosen in the fall term of 2015 included: Volkswagen emissions cheating; nuclear waste storage in Ontario; Energy East pipeline approval; sale of Hydro One in Ontario; and mandatory vaccinations in Canada.

This dynamic component encouraged students to focus on understanding problems that were not static in nature. The problem could not be studied and resolved in isolation of the public and political discourse. It also presented students with the additional challenge of learning to interact with external information as they worked on their projects and appreciate that new information, actors, and opinion may come to light that would force them to constantly re-evaluate their positions.

2.3.3 Real-Time Feedback Meeting Style. This unique element of the course was designed to reinforce real-life group work, project management, and client management. Rather than submitting written updates to the teaching assistant or instructor, students provided in-person updates during meeting or presentation scheduled during tutorial times based on the aforementioned three-week rotation. Students received immediate feedback during the meeting or presentation. As such, students could debate the merit of the advice being provided and/or clarify specific points. Further to this, students did not have to wait to receive feedback on their work. In addition, student groups were required to produce meeting minutes which allowed for further clarification of the discussion as well as documented specific follow-up actions.

All progress meetings and presentations were held only with the student group members and course instructional staff (with the exception of the final presentation where other faculty members were invited to attend). Meetings were held in boardrooms rather than classrooms with a focus on an interactive meeting/presentation style (where the instructional staff interrupted during the presentations to ask questions and clarify information) rather than lecture/conference style. In being exposed to these professional environment simulations, students gained first-hand knowledge of group interaction and feedback mechanisms similar to those used in contemporary workplaces.

\section{STUDENT FEEDBACK}

At the completion of the course, students were asked to participate in a confidential survey and focus group with facilitators from the McMaster Institute for Innovation \& Excellence in Teaching \& Learning (MIIETL). Twelve students participated in the focus group which represented approximately $12 \%$ of the enrolled students. The survey and focus group were conducted without the instructional team present. Only the aggregated results and comments were shared with the instructional team by MIIETL. In addition to the survey and focus group, end of term course evaluations provided additional feedback and comments. However, these did not provide the same quality of information as the survey and focus group due to the generic nature of the course evaluations. As such, the results shared in the paper reflect the specific outcome of the survey and focus group with respect to student feedback on the course.

\subsection{Three-Week Rotation of Learning}

In general, students appreciated the three-week rotation "as a welcome change from a typical lecturelisten format" [10]. However, the groups that were in the later time slots (i.e. third week of the rotation) felt that they were behind the rest of the class [10]. Further to this, students suggested a mid-term break from the rotation for an opportunity for a "check-in" by all groups with the instructor [10]. Students also appreciated the detailed project guidance document but they may have had some challenges understanding the expectations as shown in Figure 2 [10]. This may suggest that an opportunity exists to further clarify expectations for the meetings due to the uniqueness of this approach in the B. Tech. program. Unlike assignment, project, or examination expectations; 
meeting expectations may not be as clearly understood due to a lack of exposure to such criterion. Fig. 2 shows the responses of the two focus group survey questions: 1) How clear were the expectations for each meeting with the TA; and, 2) How clear were the expectations for each meeting with the instructor.

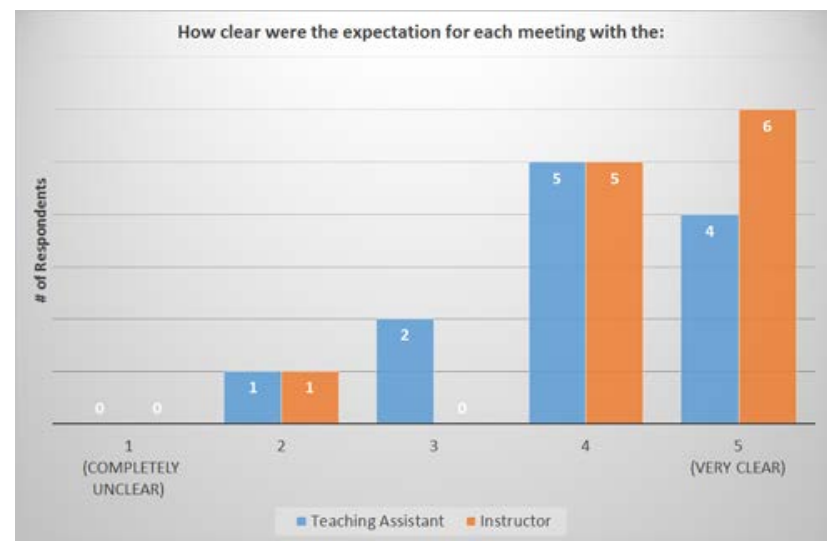

Fig.2. Meeting expectations clarity

\subsection{Dynamic Nature}

Students "described the project as their 'greatest intellectual challenge' of the B. Tech. program” [10]. Considering other research and business projects are part of the B. Tech. program, it could be inferred that the dynamic nature of the project was a contributing factor to this challenge as an element that is unique to this course. This challenge also exists with respect to the instruction team. The instructional team must be engaged and remain current in the topics undertaken by the students in order to create and maintain this challenge, which requires coaching and ongoing support by the teaching assistant(s) and instructor. The idea of the topics being self-selected and engagement with the material was positively reflected on by the students [10], which would be expected. The removal of self-selection may have a negative impact on student engagement with the course and material.

\subsection{Real-Time Feedback Meeting Style}

Student responses on the real-time feedback and meeting style were perhaps the most telling aspect of the focus group. Students clearly expressed their preference for presenting in a boardroom compared to a lecture/conference style presentation as shown in Fig. 3. Only one out of 12 students surveyed stated that a presentation in front of a classroom was preferred [10].

Further to this, most students surveyed expressed that the progressive meeting format helped to keep them on track throughout the term as shown in Fig. 4 [10]. The instructional staff engagement and prompt response to meeting minutes and clarification is an important aspect of ensuring that students remain on track. The promptness of the response is made either by 1) immediate verbal feedback from the instructional staff to the students during meetings/presentation or, 2) the expectation on students to seek out clarification through meeting minutes.

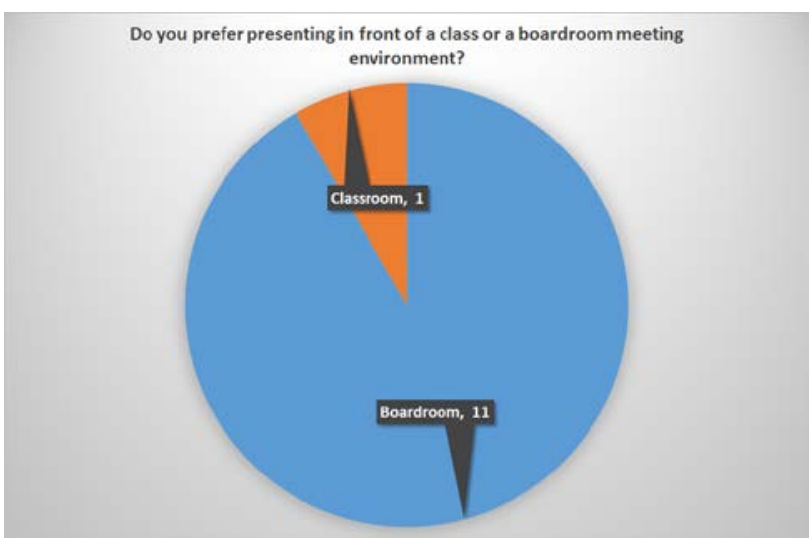

Fig.3. Student presentation preferences

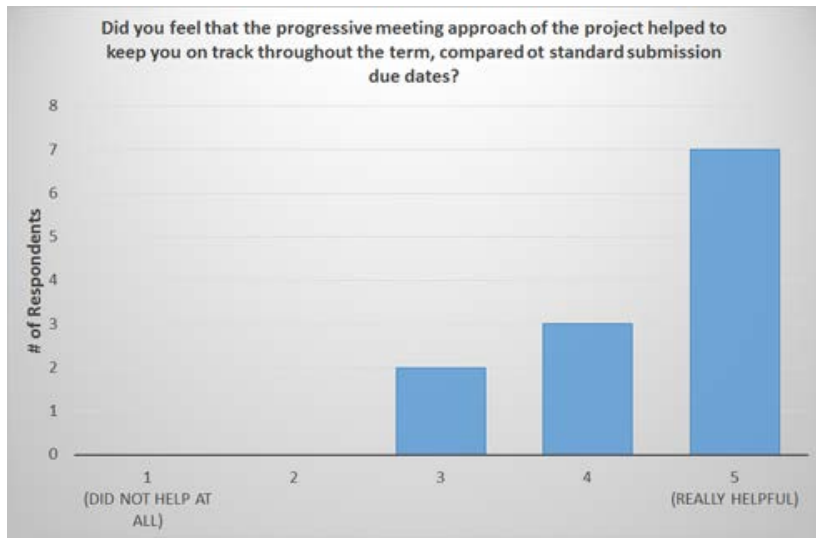

Fig.4. Progressive meeting approach

\section{DISCUSSION}

The instructional challenges are reflected in the students' comments. Firstly, the rotational schedule does not allow all groups to proceed along the same academic calendar timeline. Although the schedule is sequential in order to allow each group the same number of weeks to complete the project - the timelines were staggered. This creates administrative challenges as meetings cannot be rescheduled or rearranged based on the needs of the students or the instructional staff as these come up throughout the term. Secondly, this limits the number of students that can enroll in a single course section consisting of three hours per week. There can only be a 
maximum of nine groups per course section to allow for sufficient interaction with each group (based on the course timetable structure of 3 contact hours per week). One course section in the fall of 2015 had nine groups and it was extremely challenging for the instructional staff to maintain a schedule that allowed for equal opportunity for each group to have meaningful and unrushed interaction during meetings and presentations. Administration of a course of this nature with high enrollment and multiple class sections requires support and alignment with program administration for scheduling, and availability of a meeting space.

The theme of sustainability is not a necessity to deliver this type of experience for the students. There are numerous practices from this course which are transferrable to other topics. It is, however, important to appreciate that the student engagement was enhanced due to the relevance and timeliness of the topics. Other emerging issue type courses in engineering or business may be able to adopt a similar experiential learning approach or component into existing experiential learning courses.

Finally, clarity and direction remain a critical component of the course success. Students commented on a need for even further clarity and possibly a Q\&A style documents for the project [10]. Although a detailed guidance document was provided, future course development could include the types of questions to ask in the meetings in order to create a clearer connection to expectations for each meeting and presentation outcome.

\section{CONCLUSION}

The course offered during the fall semester of 2015 was the first of its kind for B. Tech. students. There were administrative challenges for the instructional staff to achieve the desired results that could be improved upon in future years as a result of the learning from this initial iteration. The course feedback reflects a positive and challenging experience for the students but highlights the future need to scaffold sustainability concepts throughout the B.Tech. curriculum to allow for a greater focus on project guidance, research, and delivery in the course, in a way that would further elevate both the challenge and experience for the students.

\section{Acknowledgments}

The authors wish to acknowledge the assistance of Julia Evanovitch and Jennifer Faubert from MIIETL for their facilitation of the student focus group. We would like to thank Janine Sziklasi for her exceptional work as the teaching assistant for this course. We are also indebted to Jennifer Long for her review of and feedback on this paper.

\section{References}

[1] Patricia Polastri and Todd E. Alberts, Developing A Globalized and Sustainable Mindset in 21st Century Engineering Students, Beirut, Lebanon: Committee on Education In Engineering World Federation of Engineering Organizations, March 2014, no. 18, Journal IDEAS, \{ISBN 978-9953-0-2971-9\}

[2] James Duderstadt, "Engineering for a Changing world: A Roadmap to the Future of Engineering, Practice, Research \& Education 'The Millennium Project',' University of Michigan, 2008, Available from:

http://milproj.dc.umich.edu/publications/EngFlex_report/do wnload/EngFlex\%20Report.pdf

[3] Jaco Quist, Crelis Rammelt, Mariette Overschie, and Gertjan de Werk, "Backcasting for Sustainability in Engineering Education: The Case of Delft University of Technology," Journal of Cleaner Production, vol. 14, pp. 868-876, 2006.

[4] Deborah N. Huntzinger, Margot J. Hutchins, John S., Gierke and John W. Sutherland, "Enabling Sustainable Thinking in Undergraduate Engineering Education," International Journal of Engineering Education, vol. 23, no. 2, pp. 218-230, 2007.

[5] Richard M. Felder, "On Creating Creative Engineers," Engineering Education, vol. 77, no.4, pp. 222-227, 1987.

[6] J. C. Wise, S. H. Lee, T. Litzinger, R. M. Marra and B. Palmer, "A report on a four-year longitudinal study of intellectual development of engineering undergraduates," Journal of Adult Development, vol. 11, no.2, 2004.

[7] Dietrich V. Queis, "Education for Sustainable Development: Implications for Teaching in Higher Education," Paper to 11th UNESCO-APEID Conference Reinventing Higher Education: Toward Participatory and Sustainable Development, 2007. Available from: http://www.unescobkk.org/fileadmin/user_upload/apeid/Co nference/11thConference/papers/1B1_Dietrich_v_Queis.pd $\mathrm{f}$

[8] Helen Dobson and Bland Tomkinson, Practical Education for Sustainable Development through Interdisciplinary Problem-based Learning. York, UK: The Higher Education Academy, 2013, Chapter 3, \{ISBN: 978-1-907207-69-3\}

[9] Scaffold Learning: A Blueprint for building sustainable managers, Network for Business Sustainability. Available as of March 20, 2016 from http://nbs.net/sustainabilitycentres/scaffold-learning-a-blueprint-for-buildingsustainable-managers-2/

[10] Julia Evanovitch and Jennifer Faubert, “Course Refinement Feedback,” McMaster Institute for Innovation \& Excellence in Teaching \& Learning (MIIETL), Available as of December 7, 2015 to G. Zilberbrant. 